\title{
The Characterization of L-Alanine crystals using band gap,microhardness and non-linear studies.
}

\author{
N.Muruganantham ${ }^{1}$ P.Anitha ${ }^{2}$ \\ ${ }^{I}$ Assistant professor,Department of Chemistry.Roever Engineering college ,Perambalur,Tamil nadu.India \\ ${ }^{2}$ Assistant professor,Department of Physics.Roever college of engineering and Technology,Perambalur,Tamil \\ nadu.India.
}

\begin{abstract}
The hardness of the crystals was determined by Vicker's Hardness test. The energy band gaps were also reported for each crystal. These crystals have been characterized by optical and mechanical studies. The decomposition temperatures and weight loss have been estimated from the Thermo Gravimetric Analysis and Differential Thermal Analysis and hardness was found from the Vicker's microhardness measurement. In the present work, pure crystals of L-Alanine, $\mathrm{HCl}, \mathrm{KCl}$ and $\mathrm{KDP}$ mixed L Alanine crystals have been grown by slow evaporation method.
\end{abstract}

Key words: Vicker's microhardness, bandgap, Thermal analysis,alanine,etc.,

\section{Introduction}

The degree of purity and perfection of crystals are to be known to interpret the structure dependent properties in order to determine whether the material can be successfully employed in the experiments or in the device fabrication process. It is also important to know the nature and distribution of the imperfections present in the crystals. A thorough assessment can only determine the quality and perfection of the crystals and their properties.

Detailed studies of the crystals can provide clues to deduce how the growth techniques should be modified so that the perfection of the crystal may be increased. Characterization of a crystal essentially consists of its chemical composition, structure, defects and the study of their electrical, mechanical and optical properties. The study of the growth defects includes the defects such as inclusions, step growth, mechanical stress etc., which result due to poor control of crystal growth parameters.

In the field of nonlinear optical crystal growth, amino acids are playing a vital role. Many numbers of natural amino acids are individually exhibiting the nonlinear optical properties because they have a donor $\mathrm{NH}_{2}{ }^{+}$and acceptor $\mathrm{COOH}^{-}$and also intermolecular charge transfer is possible. Especially natural amino acids of aspartic and glutamic and as well as Arginine, Lysine, L-Alanine and Y-glycine are evidently showing NLO activity because of an additional $\mathrm{COOH}$ group in the first and $\mathrm{NH}_{2}$ group in the second. Also, some of the amino acids are used as dopants and they enhance the material properties like Non linear optical and ferroelectric properties. A series of semi-organic compounds such as L-Alanine, L-Arginine diphosphate crystals have been reported with moderately high mechanical and chemical stability.

\section{Property and structure of L-alanine}

The structure of L - Alanine has been solved by West (1930) and it was later confirmed by Frazer and Pepinsky (by X-ray diffraction studies) and Bawn and Pease (by neutron diffraction studies).

$\mathrm{L}$-alanine belongs to the space group is $\mathrm{P} 2_{1}, 2_{1}, 2_{1}$. The unit cell dimensions are $\mathrm{a}=6.023 \AA \mathrm{b}=12.343 \AA, \mathrm{C}=$ $5.784 \AA ; \alpha=\beta=\gamma=90^{\circ}$ obtained from the analysis are given in the table- 1

Table -1Crystallographic Data of L-Alanine
\begin{tabular}{|c|c|}
\hline $\begin{array}{c}\text { Chemical } \\
\text { Formula }\end{array}$ & $\mathrm{CH}_{3} \mathbf{C H N H}_{2} \mathbf{C O O H}$ \\
\hline $\begin{array}{c}\text { Molecular } \\
\text { Weight }\end{array}$ & 89.09 \\
\hline Space group & $\mathrm{P} 2_{1} 2_{1} 2_{1}$ \\
\hline $\mathrm{A}$ & $6.023 \AA$ \\
\hline $\mathrm{B}$ & $12.343 \AA$ \\
\hline $\mathrm{C}$ & $5.784 \AA$ \\
\hline$\alpha=\beta=\gamma$ & $90^{\circ}$ \\
\hline
\end{tabular}

- Member of amino acids

- Strongest basic amino acids

- Chemical formula $\mathrm{CH}_{3} \mathrm{CHNH}_{2} \mathrm{COOH}$

- Orthorhombic crystal system 
- Molecular weight is $89.1 \mathrm{gm}$

- Melts with decomposition of $297^{0} \mathrm{C}$

- High solubility in water and insoluble in diethyl ether

- Having 99\% purity

- Appearance : White power

- Having high stability

\section{Bandgap}

\section{Materials and methods:}

In solid state physics and related applied fields, the band gap, also called an energy gap or stop band, is a region where a particle or quasiparticle is forbidden from propagating. For insulators and semiconductors, the band gap generally refers to the energy difference between the top of the valence band and the bottom of the conduction band.

In semiconductors and insulators, electrons are confined to a number of bands of energy, and forbidden from other regions. The term "band gap" refers to the energy difference between the top of the valence band and the bottom of the conduction band, where electrons are able to jump from one band to another. The bandgap energy $\mathrm{E}_{\mathrm{g}}$ can be calculated by using the relation $\alpha=\left[A_{o}\left(h v-E_{g}\right)^{1 / 2}\right] / h v$

where $A_{o}$ is the constant which is related to the effective masses associated with the band gap. $E_{g}$ is the bandgap energy. $\alpha$ is the absorption coefficient.

\section{Microhardness measurements}

The good quality of the organic crystals is very much needed for device fabrication. In single crystals, the second harmonic generation is always lower from the defective sectors compared with that from the more perfect sectors. The good quality crystals are needed not only with good optical performance but with good mechanical behaviour. Hardness of the material is the resistance it offers to indentation by a much harder body. An important use of microhardness studies is the possibility of making indirect estimate of other mechanical characteristics of materials having a specific correlation with their hardness.

The hardness depends not only on the properties of the material under test but also largely on the conditions of measurements. Hardness is an important factor in the choice of ceramics for abrasives, tool bits, bearings and wear resistant coatings and it generally correlates with both micro and macro plastic deformation and with the ease of machining. It may be termed as a measure of the resistance against lattice destruction or the resistance offered to permanent deformation or damage.

\section{Vicker's Microhardness Studies}

In the present investigation, the microhardness of the grown crystals, of L-alanine was determined using the static indentation test with Vicker's diamond pyramid indentor at room temperature. Selected smooth surface of the grown crystals of L-alanine was subjected to the Vicker's static indentation test. The static indentation test was carried out at room temperature using a Vicker's diamond pyramidal indentor attached to Leiz Wetzler a microscope. The Vickers hardness test method consists of indenting the test material with a diamond indenter, in the form of a right pyramid with a square base and an angle of $136^{\circ}$. The loads varying from $10 \mathrm{~g}-50 \mathrm{~g}$ were applied over a fixed interval of time. The full load is normally applied for 10 to 15 seconds. The two diagonals of the indentation left in the surface of the material after removal of the load are measured using a microscope and their average calculated.

The area of the sloping surface of the indentation is A Indentations were made at different sites such that the distance between any two indentations was greater than three times the diagonal length, in order to avoid any mutual influence of the indentations. Diagonal lengths of the indented impression obtained at various loads were measured using micrometer eyepiece at a magnification of 500. The Vicker's micro-hardness number against load $(\mathrm{g})$ is determined by actual area of impression. Harness value on the $\{011\}$ face of LAlanine crystal was estimated for different loads. Several trials of indentations at each load were carried out and the hardness number was estimated using,

Where,

$$
H_{v}=1.8544 * W / d^{2} \mathrm{~kg} / \mathrm{mm}^{2}
$$

$$
\begin{aligned}
& \mathrm{H}_{\mathrm{v}}=\text { Vickers microhardness number } \\
& \mathrm{W}=\text { applied load } \\
& \mathrm{d}=\text { Diagonal length of the indentation } \\
& \text { impression in metre. }
\end{aligned}
$$


The Characterization of L-Alanine crystals using band gap,microhardness and non-linear studies.

\section{Bandgap energy}

The bandgap energy were calculated from the UV transmittance graph by taking $\mathrm{h} v$ values in $\mathrm{x}$ axis and $(\alpha h v)^{2}$ for the above crystals. The bandgap energy for pure L-Alanine, $\mathrm{HCl}, \mathrm{KCl}$, and $\mathrm{KDP}$ mixed LAlanine was calculated from the graph. The bandgap graphs for L-Alanine family crystals are shown in Fig.1,2,3and4.

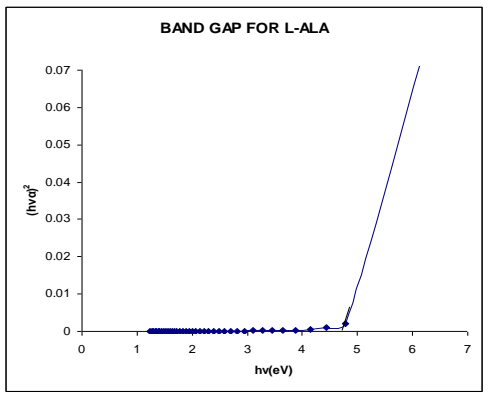

Fig.1 Bandgap Calculation Of pure L-Alanine crystal

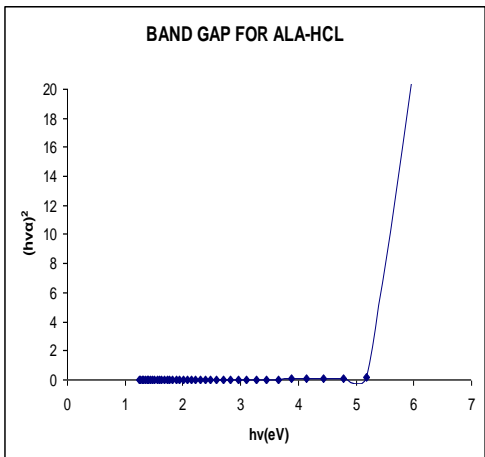

Fig-2 Bandgap Calculation Of HCl mixed L-Alanine

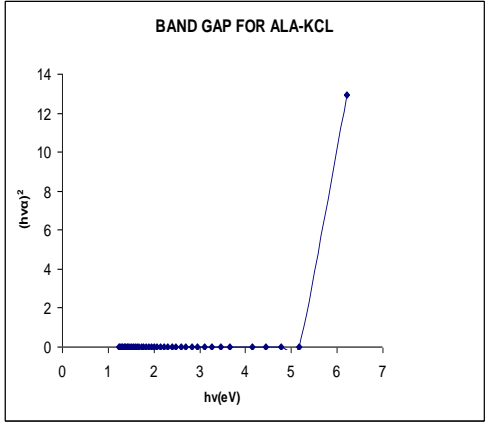

Fig-3 Bandgap Calculation KCl mixed L-Alanine crystal

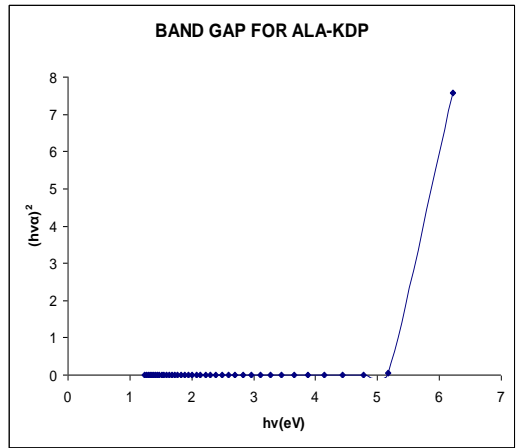

Vicker's Hardness studies:

Fig(4.13) Bandgap Calculation Of KDP Mixed L-Alanine crystal

The Vicker's hardness test was carried out for pure L-Alaline and $\mathrm{KCl}$ mixed L-Alanine crystals and the hardness number $\left(\mathrm{H}_{\mathrm{v}}\right)$ is determined at room temperature for the above crystals are listed in the Tables 2,3. 
The Characterization of L-Alanine crystals using band gap,microhardness and non-linear studies.

Table-2 Hardness number for pure L-Alanine crystal

\begin{tabular}{|c|c|}
\hline Load(gm) & $\begin{array}{c}\text { Hardness } \\
\text { Number }\left(\mathbf{H}_{\mathbf{V}}\right)\end{array}$ \\
\hline 25 & 45.7 \\
\hline 50 & 60.5 \\
\hline 100 & 63.9 \\
\hline 200 & 71.6 \\
\hline 300 & 64.0 \\
\hline
\end{tabular}

Table-3 Hardness number for KCl mixed L-Alanine crystal

\begin{tabular}{|c|c|}
\hline Load(gm) & Hardness Number $\left(\mathbf{H}_{\mathbf{V}}\right)$ \\
\hline 25 & 6.04 \\
\hline 50 & 9.38 \\
\hline 100 & 15.5 \\
\hline 200 & 22.4 \\
\hline
\end{tabular}

Graphs were drawn between the hardness number $\mathrm{H}_{\mathrm{v}}$ and the load $\mathrm{P}$ for the above crystals and are listed in Fig.5,6.

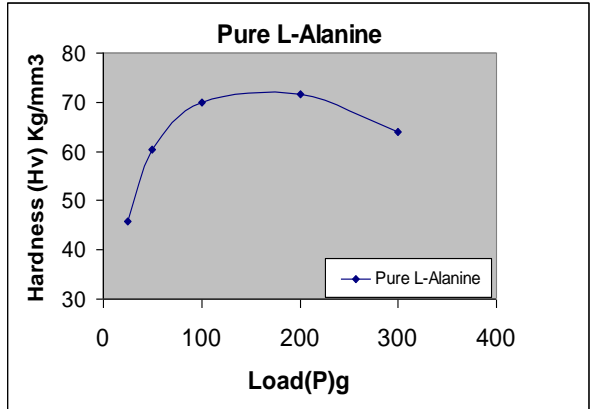

Fig -5 Hardness curve for L-Alanine crystals

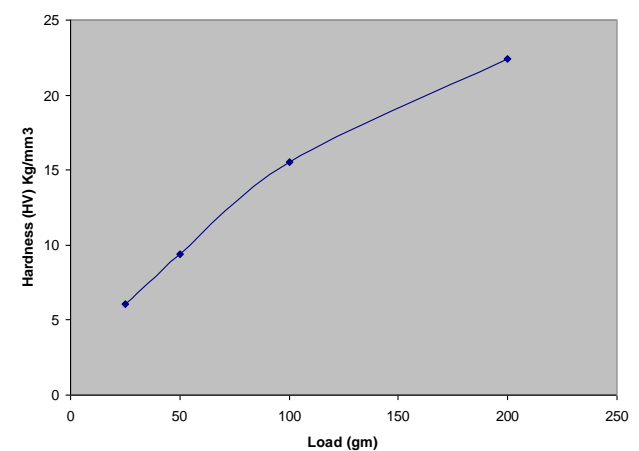

Fig-6 Hardness curve for KCl mixed L-Alanine crystals

\section{Bandgap energy studies}

\section{Result and discussion:}

From the band gap the corresponding band gap energies of the pure L-Alanine $\mathrm{HCl}, \mathrm{KCl}$ and $\mathrm{KDP}$ mixed L-Alanine were $4.99 \mathrm{eV}, 5.176 \mathrm{eV}, 5.184 \mathrm{eV}, 5.201 \mathrm{eV}$, respectively. Which sows that by the addition of $\mathrm{HCl}, \mathrm{KCl}, \mathrm{KDP}$ increases the band gap.

\section{Hardness studies}

Loads of $25,50,100,200,300 \mathrm{~g}$ were used for micro hardness studies.. The Hardness number is measured using $\mathrm{Hv}=1.8544 \mathrm{P} / \mathrm{d} 2\left(\mathrm{~kg} / \mathrm{mm}^{2}\right)$. The above tables and figures show the relation between the hardness number and load. The hardness of L-Alanine family crystal was increases with increase of load. If we again increasing the load the start to decreasing. At lower loads hardness is relatively low and it increases for higher loads and remain constant up to $300 \mathrm{~g}$. Above $300 \mathrm{~g}$ load, significant cracking occurs due to the release of internal stress generated locally by indentation. The bond energy of the crystal is believed to cause the higher hardness values at lower loads. 


\section{Conclusion}

Good quality of L-Alanine, $\mathrm{HCl}, \mathrm{KCl}$, and $\mathrm{KDP}$ mixed L-Alanine crystals were grown by slow evaporation method. These crystals were characterized by FT-IR, UV visible spectrum, micro hardness testing and band gap energy study. Hardness test is useful to find the mechanical hardness of the crystal and to estimate the threshold mechanical stress. Vicker's hardness measurement of pure L-Alanine $\mathrm{HCl}, \mathrm{KCl}$ and $\mathrm{KDP}$ mixed L-Alanine were studied. It is an important requirement for the materials having NLO properties. The mechanical strength of pure and $\mathrm{KCl}$ mixed L-Alanine crystals were reported using Vicker's hardness test.

From the above studies, it is concluded that the optical and mechanical properties of the crystals can be tuned as per our requirements.

\section{Reference}

[1] Gilman, J.J Ed., (1963), "The Art and Science of growing Crystals", John Wiley \& Sons, Inc, New York, London.

[2] Kittel, C. (1977), "Introduction to Solid State Physics", Wiley Eastern Limited, New Delhi.

[3] Brice, J.C (1965), “Crystal Growth Processes", John Wiley \& sons, New York.

[4] Brice, J.C (1965), "The growth of crystals from the Melt", (North Publishing Company, Amsterdam.

[5] Ramasamy, P., C. Subramaniam and R. Dhanasekaran (1986), "Proceedings of UGC summer school on crystal growth and characterization of Advanced Materials for solid state applications".

[6] Pfann, W.G(1964), J. Appl. Phys., 35,258.

[7] Bulakh, B.M (1970), J. Cryst. Growth, 7,196.

[8] Henisch, H.K (1986), "Crystal in Gels and Liesegang Rings",(Cambridge University

[9] Henisch, H.K (1980, "Crystals in Gels and Lisegang Rings", (Cambridge University Press, Cambridge)

[10] Blank, Z., D.M. Speyer, W. Brenner \& L.O Kamoto ('1987), "Nature", 16, 1103.

[11] Arora, S.K. (1982),’Prog. Crystal Growth Charact.", 4,345.

[12] Patel, A.R. and A. Venkateswara Rao (1982), "Bull Mater.Sci.",4,527.

[13] Henisch, H.K. (1970), "Crystal Growth in Gels", The Pennysylvania State University Press, University Park.

[14] Glocker, D.A and J.F Soest (1969), “J. Chem. Phy.”, 51,3143.

[15] Joshi, M.S. and A.V. Antony (1978), "J. Mat.Sci.", 13,939.

[16] Desai, M.S. and J.L. Rai (1980), “Krist Un Tech.”, 15,115.

[17] Arora, S.K. (1982),’Prog. Crystal Growth Charact.", 4,345.

[18] B.R. Pamplin, "Progress in crystal growth and Characterization", Vol.2 Porgamon Press, New York 1979.

[19] Psahay. R.K. Nath and S. Tewari': crystal. res. technol'” 42 (2007) 275-280.

[20] D. Rayan Babu, D. Jayaraman R. Mohan Kumar R. Jayavel'’ Journal of Crystal Growth, 245[2002]121-125. 